\title{
Roles and mechanisms of leptin in osteogenic stimulation in cervical ossification of the posterior longitudinal ligament
}

\author{
Bin Feng ${ }^{\dagger}$, Shiliang $\mathrm{CaO}^{\dagger}$, Jiliang Zhai, Yi Ren, Jianhua Hu, Ye Tian ${ }^{*}$ and Xisheng Weng ${ }^{*}$ (1)
}

\begin{abstract}
Background: Hyperleptinemia is a common feature of obese people, and leptin, an adipocyte-derived cytokine, is believed to be an important factor in the pathogenesis of cervical ossification of the posterior longitudinal ligament(C-OPLL). So this research was to identify the relation between the serum leptin and bone metabolic markers and how the leptin induced osteogenic effect in C-OPLL.

Methods: Sixty-four samples were selected to determine the concentration of leptin, insulin, and alkaline phosphatase. And the association of leptin with these factors was also examined. We also evaluate the effect of leptin on the development of C-OPLL and further explored the possible underlying mechanism in vitro.

Results: We found that serum leptin concentrations were higher in females than in males. Serum leptin and ALP concentrations were increased significantly in C-OPLL females compared to non-OPLL females. In OPLL subjects, the serum leptin concentration corrected for body mass index correlated negatively with the ALP concentrations. In C-OPLL cells, leptin treatment led to a significant increase in MRNA expressions of ALP and OCN and formation of mineralized nodule. Our experiments reported here that osteogenic effect of leptin in C-OPLL cells could be mediated via ERK1/2, p38 MAPK, and/or JNK signaling pathways.

Conclusions: From this research, we got that leptin treatment led to a significant increase in mRNA expressions of ALP and OCN and formation of mineralized nodule. And the osteogenic effect of leptin in C-OPLL cells could be mediated via ERK1/2, p38 MAPK, and/or JNK signaling pathways.
\end{abstract}

Keywords: Leptin, Ossification of the posterior longitudinal ligament (OPLL), Gender, Bone metabolic markers, Signaling pathway

\section{Background}

Ossification of the posterior longitudinal ligament (OPLL) is a common musculoskeletal disease, characterized by ectopic bone formation of the spinal ligament preferentially at the cervical spine $[1,2]$. As OPLL commonly involved in cervical spine resulting in myelopathy or radiculopathy, in this condition, we said it cervical OPLL(C-OPLL). Enlarged ossified ligament compresses

\footnotetext{
*Correspondence: TianYe@pumch.cn; DoctorWXS@126.com

${ }^{\dagger}$ Bin Feng and Shiliang Cao contributed equally to this work.

Department of Orthopedics Surgery, Peking Union Medical College Hospital, Chinese Academy of Medical Sciences \& Peking Union Medical College,
} Beijing 100730, China

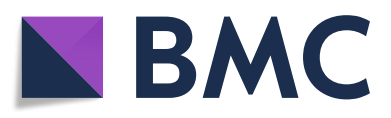

(c) The Author(s). 2018 Open Access This article is distributed under the terms of the Creative Commons Attribution 4.0 International License (http://creativecommons.org/licenses/by/4.0/), which permits unrestricted use, distribution, and

reproduction in any medium, provided you give appropriate credit to the original author(s) and the source, provide a link to the Creative Commons license, and indicate if changes were made. The Creative Commons Public Domain Dedication waiver (http://creativecommons.org/publicdomain/zero/1.0/) applies to the data made available in this article, unless otherwise stated.

the spinal cord and nerve roots, eventually leads to the neurological deficit $[3,4]$. Its prevalence is higher among Asian populations, and in Chinese populations, the average prevalence is reported to be $3.08 \%$ [5-8].

Although the exact pathogenesis of C-OPLL remains unclear, leptin is supposed to be an important factor in the pathogenesis of C-OPLL. Leptin, a product of the ob gene which is expressed by adipocyte tissue and released into circulation, is a prominent regulator of body weight and fat $[9,10]$. Investigations have indicated that leptin can stimulate the proliferation and osteogenic differentiation of embryonic cells, bone marrow stromal cells (BMSCs), and osteoblastic cells [11-13]. Leptin has been found to have 
both positive and negative effects on bone mass [14]. Leptin positively regulates bone formation through direct actions on bone, when administrated peripherally [10, 15], and suppresses bone formation and increases resorption through a hypothalamic relay, when infused centrally [16]. Previous study indicates that serum leptin may be associated with the development of heterotopic ossification of the spinal ligament [17]. However, the association between leptin and OPLL is still controversial and needs to be clarified further. And the mechanism of leptin in the development of OPLL has seldom been studied.

In this study, to clarify the association between leptin and C-OPLL, we measured serum leptin concentrations in C-OPLL patients and non-OPLL controls and corrected these levels using individual body mass index (BMI). Then, we analyzed the possible mechanism of leptin in the development of OPLL in vitro.

\section{Methods \\ Patients}

Totally, 64 samples were used for the research, including 35 cervical OPLL (24 males and 11 females) patients who underwent anterior cervical decompression surgery and 29 non-OPLL (15 males and 14 females) controls; the majority of who had cervical degenerative disorders were enrolled into this study. The diagnosis of cervical OPLL was confirmed by computer tomography (CT), $\mathrm{X}$-ray photographs, and magnetic resonance imaging (MRI) of the cervical spine. This study was approved by the Ethics Committee of Peking Union Medical College Hospital, and informed consents were obtained from all patients.

Previous data indicated that there are important gender-based differences in the regulation and action of leptin in humans, and leptin levels are higher in women than in men. We subdivided the OPLL and non-OPLL groups according to gender. The mean age of OPLL males, non-OPLL males, OPLL females, and non-OPLL females was $59.04 \pm 9.32,57.40 \pm 11.04,57.25 \pm 8.68$, and $61.95 \pm 10.93$ years, respectively. The mean BMI (weight in kilograms divided by the square of height in meters) of the four groups was $26.47 \pm 3.46,25.26 \pm 4.46,25.49 \pm$ 3.05 , and $24.1 \pm 3.37 \mathrm{~kg} / \mathrm{m}^{2}$, respectively.

\section{Blood samples}

Blood samples were collected from all patients between 8:00 and 10:00 after overnight fasting and the serum immediately frozen at $-80{ }^{\circ} \mathrm{C}$ until analysis. Serum leptin and insulin concentrations were measured using a commercially available enzyme-linked immunosorbent assay (ELISA) kit (Elabscience). The serum concentrations of bone formation markers, alkaline phosphatase (ALP), were measured using BCIP/NBT ALP Color Development Kit (Beyotime Biotechnology). The concentration of glycosylated serum protein (GSP), which can effectively reflect the average glucose concentration of the patients in the past 2 3 weeks, was also detected using GSP test kit (Solarbio life sciences).

\section{Spinal ligament samples}

During the anterior cervical decompression surgery, posterior longitudinal ligament specimens were aseptically harvested from OPLL patients and rinsed with phosphate-buffered saline. Surrounding tissue was carefully removed under a dissecting microscope.

\section{Cell cultures}

The collected ligaments were mincing into approximately $0.5 \mathrm{~mm}^{3}$ pieces and washed twice with phosphate-buffered saline (PBS). Then, the ligament fragments were plated into $6 \mathrm{~cm}$ culture dishes and maintained in low-glucose Dulbecco's modified Eagle's media (DMEM) (supplemented with 10\% FBS, 1\% L-glutamine, 100 units $/ \mathrm{ml}$ of penicillin $\mathrm{G}$ sodium, $10 \mathrm{mM}$-glycerophosphate, and $100 \mu \mathrm{g} / \mathrm{ml}$ of streptomycin sulfate) in a humidified atmosphere of $95 \%$ air and $5 \% \mathrm{CO}_{2}$ at $37{ }^{\circ} \mathrm{C}$. The cells derived from the explants were removed from the dishes with $0.02 \%$ EDTA, $0.05 \%$ trypsin for further passage. The first to third passage cells were used in the following study.

\section{CCK8 assay}

Cell proliferation was measured by CCK8 dye reduction assay. Briefly, $5 \times 10^{3}$ cells were seeded into 96-well plates overnight and exposed to the leptin at distinct concentrations $(0,50,100,200,400 \mathrm{ng} / \mathrm{ml})$ for different times ( 4 and 7 days). Then, the cells were incubated with $10 \mu \mathrm{l}$ of CCK8 for $1 \mathrm{~h}$ at $37{ }^{\circ} \mathrm{C}$. The absorbance was measured at $450 \mathrm{~nm}$ using a microplate reader.

\section{Real-time PCR}

$3 \times 10^{6}$ cells in logarithmic phase were plated into 6-well dishes for $24 \mathrm{~h}$, then the cells were exposed to the leptin at different concentrations $(0,50,100,200 \mathrm{ng} / \mathrm{ml})$. After $96 \mathrm{~h}$, total RNA was extracted from the cells using Trizol reagents (Invitrogen), and the RNA concentration was detected. Two micrograms of total RNA were reverse-transcribed using Reverse Transcription Kit (Invitrogen) for real time-PCR (RT-PCR). Primers used for amplification were as follows: ALP, 5' -TCCCAGTTG AGGAGGAGAA-3' (forward), 5'-CCAGGAAGATGAT GAGGTTC-3' (reverse); osteocalcin (OCN), 5' 'AGCG $^{\prime}$ AGGTAGTGAAGAGAC-3' (forward), 5' -CCTGAAAGC CGATGTGGT-3' (reverse); $\beta$-actin, 5 '-ATCATGTTTGA GACCTTCAACA-3' (forward), 5'-CATCTCTTGCTCGA AGTCCA3' (reverse). Polymerase chain reaction amplification was carried out in a volume of $25 \mu \mathrm{l}$ containing $12.5 \mu \mathrm{l} 2 \times$ PCR mix, $10.5 \mu \mathrm{l}$ nuclease-free water, $1 \mu \mathrm{l}$ 
cDNA, and $1 \mu \mathrm{l}$ primer. The melting curves were also prepared during the amplifications. All products were normalized to $\beta$-actin mRNA levels. Each specimen was repeated three times.

\section{Mineralization assay}

$1 \times 10^{4}$ cells were plated into 12 -well dishes and maintained in DMEM with 10\% FBS. On confluence, designated day 0 , cells were exposed to leptin medium containing DMEM supplemented with 10\% FBS, 1\% L-glutamine, 100 units/ml of penicillin $\mathrm{G}$ sodium and $100 \mu \mathrm{g} / \mathrm{ml}$ of streptomycin sulfate, $10 \mathrm{mM}$-glycerophosphate, and $100 \mathrm{ng} / \mathrm{ml}$ leptin. Alizarin red assay (Sigma) was performed at 72 and $96 \mathrm{~h}$ to determine the mineralization. Briefly, cells were washed with D-hank's and fixed with $4 \%$ paraformaldehyde for $20-30 \mathrm{~min}$ at room temperature. Fixed cultures were incubated with $1 \%$ alizarin red for $20-30 \mathrm{~min}$ at $37{ }^{\circ} \mathrm{C}$ and washed with distilled water for three times to remove the excessive dye. Extracellular matrix mineral-bound stains were visualized and photographed under a microscope.

\section{ALP activity assay}

ALP activity was evaluated using commercially available kits. Cells were cultured in 6-well plates for 3-5 h and exposed to the leptin at different concentrations $(0,50$, 100, $200 \mathrm{ng} / \mathrm{ml}$ ). After $96 \mathrm{~h}$, cells were washed with PBS and fixed in $4 \%$ polyoxymethylene for $10 \mathrm{~min}$, and stained with BCIP/NBT ALP Color Development Kit (Beyotime Biotechnology) according to the manufacturer's instructions.

\section{Western blotting}

Cells were harvested, and equal amounts of protein were loaded onto $10 \%$ sodium dodecyl sulfate polyacrylamide gel electrophoresis (SDS-PAGE) gels for $2 \mathrm{~h}$ at $100 \mathrm{~V}$ and subsequently transferred onto polyvinylidene difluoride (PVDF) membranes (Millipore). The membrane was blocked with 5\% skim milk for $1 \mathrm{~h}$ at room temperature. After washing three times with Tris-buffered saline (TBS) containing $0.1 \%$ Tween 20 (TBST), the membranes were incubated with appropriately diluted Phospho-p44/42 MAPK, p44/42 MAPK, Phospho-JNK/SAPK, JNK/SAPK, Phospho-p38 MAPK, and p38 MAPK (Beyotime, Shanghai, China) antibodies at $4{ }^{\circ} \mathrm{C}$ overnight. Then, the membranes were washed as before and incubated with horseradish peroxidase-conjugated secondary antibodies (anti-mouse or anti-rabbit) for $1 \mathrm{~h}$ at room temperature. After that, these membranes were washed thoroughly, to eliminate the unspecific antibody. At last, proteins were detected using enhanced chemiluminescence (ECL) blotting reagents according to the manufacturer's instruction.

\section{Statistical analysis}

Data was analyzed using mean $\pm \mathrm{SD}$. Student's $t$ test was used to compare the data between OPLL and non-OPLL groups. Tukey's multiple comparison test was used to analyze the variance of the data and to estimate the level of significance. $p<0.05$ was considered significant.

\section{Results}

Serum leptin concentrations and leptin/BMI ratios in OPLL and non-OPLL patients

As shown in Table 1, compared with the male subjects, both non-OPLL and OPLL groups had significantly higher serum leptin concentration in females. In females, serum leptin/BMI ratio in the OPLL group was 1.6-fold higher than that in the non-OPLL group $(p<0.05)$; meanwhile, serum concentrations of bone metabolism biomarkers ALP also increased significantly $(p<0.05)$. However, in male subjects, there was no obvious difference in serum leptin concentration between the OPLL and non-OPLL groups, and ALP concentrations showed no difference either. The serum insulin concentrations were higher in OPLL groups than that in non-OPLL groups in both female and male subjects. However, the difference was not statistically significant.

Table 1 Clinical characteristics of female and male OPLL and serum concentration of leptin, insulin, and ALP

Female OPLL versus non-OPLL

\begin{tabular}{llll} 
& Non-OPLL $(n=14)$ & OPLL $(n=11)$ & $p$ (Student's $t)$ \\
Age (year) & $61.95 \pm 10.93$ & $57.25 \pm 8.68$ & N.S. \\
Height $(\mathrm{cm})$ & $1.61 \pm 0.05$ & $1.62 \pm 0.05$ & N.S. \\
Weight $(\mathrm{kg})$ & $62.79 \pm 9.86$ & $66.83 \pm 10.55$ & N.S. \\
BMl $(\mathrm{kg} / \mathrm{m})$ & $24.10 \pm 3.37$ & $25.49 \pm 3.05$ & N.S. \\
Serum leptin $(\mathrm{ng} / \mathrm{ml})$ & $22.30 \pm 9.21$ & $37.68 \pm 25.22$ & $<0.05$ \\
Leptin/BMl & $0.93 \pm 0.33$ & $1.50 \pm 0.97$ & $<0.05$ \\
Serum insulin $(\mu \mathrm{U} / \mathrm{ml})$ & $19.00 \pm 8.60$ & $22.90 \pm 13.20$ & $\quad$ N.S. \\
Serum ALP & $7.17 \pm 1.11$ & $8.05 \pm 0.73$ & $<0.05$ \\
Male OPLL versus non-OPLL & & \\
& Non-OPLL $(n=15)$ & OPLL $(n=24)$ & $p$ (Student's t) \\
Age (year) & $57.4 \pm 11.04$ & $59.04 \pm 9.32$ & N.S. \\
Height (cm) & $170 \pm 4.20$ & $170 \pm 7.07$ & N.S. \\
Weight $(\mathrm{kg})$ & $73.53 \pm 13.68$ & $76.61 \pm 12.99$ & N.S. \\
BMl (kg/m) & $25.26 \pm 4.46$ & $26.47 \pm 3.46$ & N.S. \\
Serum leptin $(\mathrm{ng} / \mathrm{ml})$ & $13.45 \pm 6.32$ & $16.69 \pm 6.90$ & N.S. \\
leptin/BMl & $0.52 \pm 0.19$ & $0.65 \pm 0.25$ & N.S. \\
Serum insulin $(\mu \mathrm{U} / \mathrm{ml})$ & $22.10 \pm 11.00$ & $29.20 \pm 30.00$ & N.S. \\
Serum ALP & $7.25 \pm 1.57$ & $7.97 \pm 1.63$ & \\
\hline & & & N.S. \\
\hline
\end{tabular}




\section{Correlation of leptin/BMI with serum insulin and} biochemical maker, ALP

To determine the factors associated with the leptin/BMI ratio in OPLL subjects, we examined the correlation between leptin/BMI ratios and serum insulin, ALP level (Fig. 1). There was only a relatively weak, non-significant positive correlation between the leptin/BMI ratio and serum insulin in females. In contrast, in male groups, the serum insulin concentration showed a weak, non-significant negative correlation with the leptin/BMI ratio. ALP concentrations were correlated negatively with the leptin/BMI ratio both in OPLL male groups and female groups, whereas male OPLL groups showed a significant correlation $(r=-0.473, p<0.05)$. There was no significant correlation between the leptin/BMI ratios and serum insulin, ALP level, in non-OPLL subjects (data not shown).

\section{Effect of leptin on the proliferation of OPLL cells}

To investigate the molecular mechanism underlying leptin-stimulated OPLL, the effect of leptin on cell proliferation of OPLL cells was evaluated by CCK 8 method. As shown in Fig. 2, the leptin had no significant effect on the proliferation of OPLL cells with various leptin concentration $(0,50,100,200 \mathrm{ng} / \mathrm{ml})$ at different periods of time ( 4 and 9 days).

\section{Effect of leptin on the osteogenic differentiation of OPLL cells}

We then examined the osteogenic differentiation of OPLL cells by RT-PCR and ALP activity assay. RT-PCR analysis showed that leptin treatment resulted in a significant increase in mRNA expression of ALP and osteocalcin (OCN) in OPLL cells, and the effect was most obvious at $50 \mathrm{ng} / \mathrm{ml}$ leptin concentration (Fig. 3a, b). ALP activity assay demonstrated that the activity of ALP was significantly elevated in response to leptin stimulation in OPLL cells, and the effect was dose-dependent (Fig. 3c).

Apart from makers of osteogenic differentiation, we further examined the formation of mineralized nodules by alizarin red staining. Mineralization assays showed that under $100 \mathrm{ng} / \mathrm{ml}$ leptin stimulation, the cell matrix began to mineralize, and crystals appeared at $72 \mathrm{~h}$. The mineralized nodules increased significantly at $96 \mathrm{~h}$ (Fig. 4a, b indicated by red arrows), compared with the absence of leptin treatment OPLL cells. There was no mineralization observed in the negative control (NC) group.
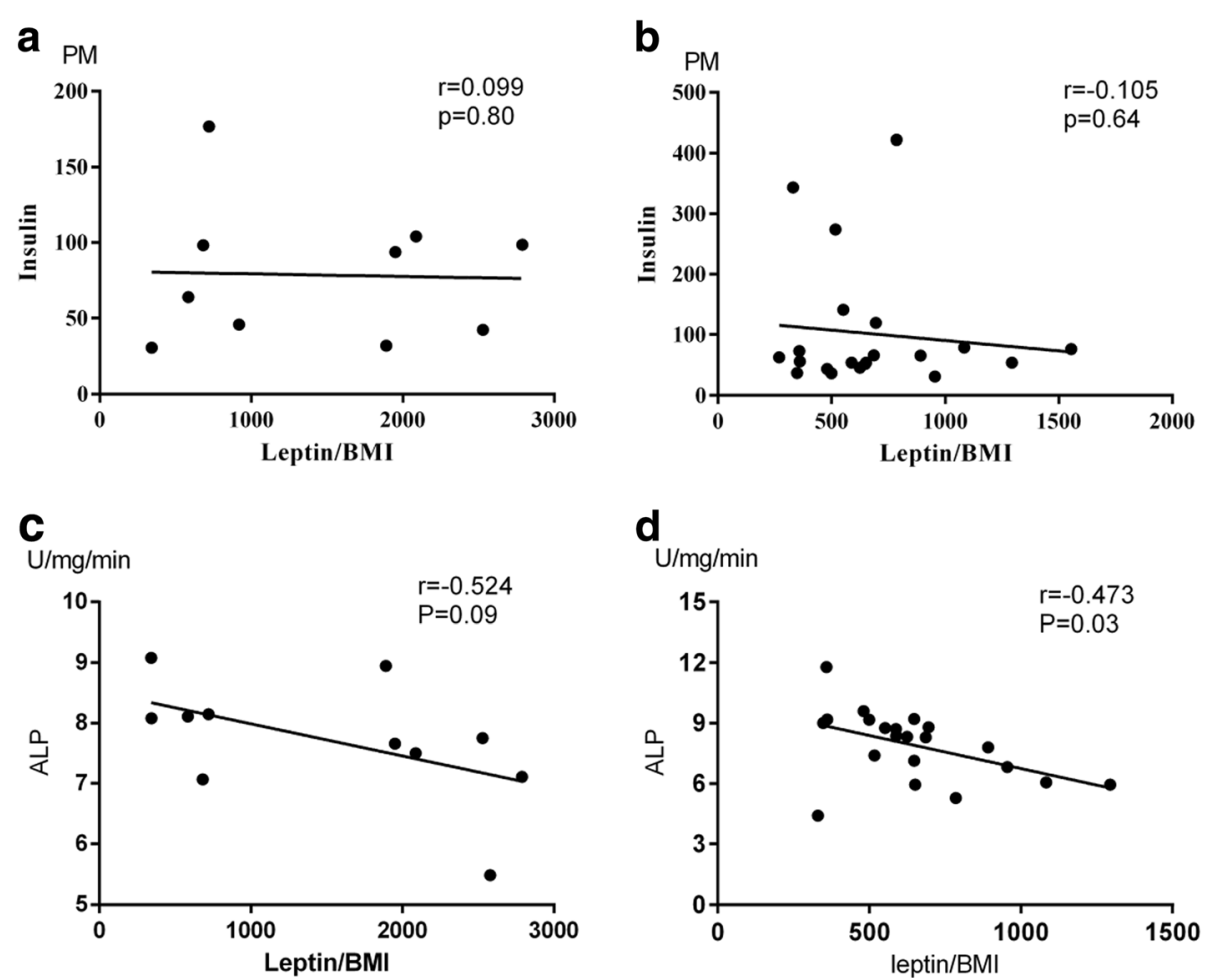

Fig. 1 Relationship between the leptin/BMI (body mass index) ratio and serum insulin and biochemical maker, ALP concentrations with female and male OPLL patients. There was a negative, significant correlation between the leptin/BMI ratio and ALP $(p<0.05)$. $\mathbf{a}, \mathbf{c}$ Females OPLL. b, $\mathbf{d}$ Males OPLL 


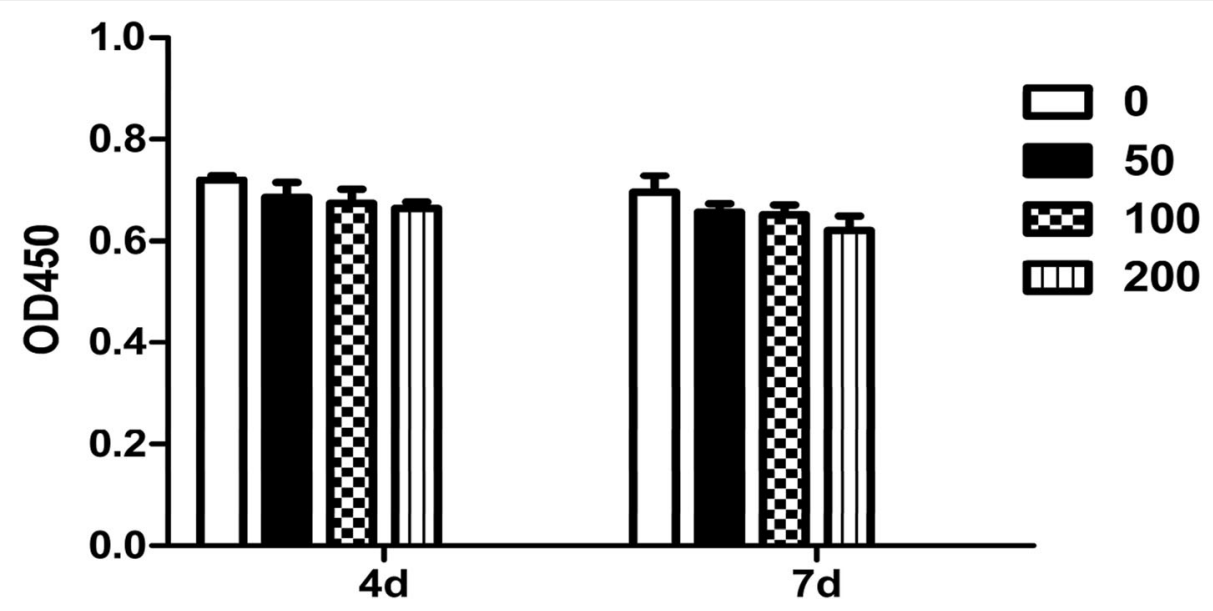

Fig. 2 Effect of leptin on the proliferation of OPLL cells

Pathways involved in the leptin-stimulated osteogenic differentiation of OPLL cells

To learn more about the mechanism underlying the osteogenic effect of leptin, we further examined the status of ERK, JNK, and p38 phosphorylation in response to leptin treatment in OPLL cells. Proteins were extracted from OPLL cells at different time after $100 \mathrm{ng} / \mathrm{ml}$ leptin treatment. The immunoblot results showed that leptin stimulated the phosphorylation of ERK1/2, p38
MAPK, and JNK in a time-dependent manner and the effect was most obvious at $1 \mathrm{~h}$, while the total expression levels of ERK1/2, p38 MAPK, and JNK were unchanged over the time of leptin treatment (Fig. 5).

\section{Discussion}

Many investigations have indicated that leptin is involved in many bone diseases [18-21]. OPLL is a common bone disease caused by heterotopic bone formation
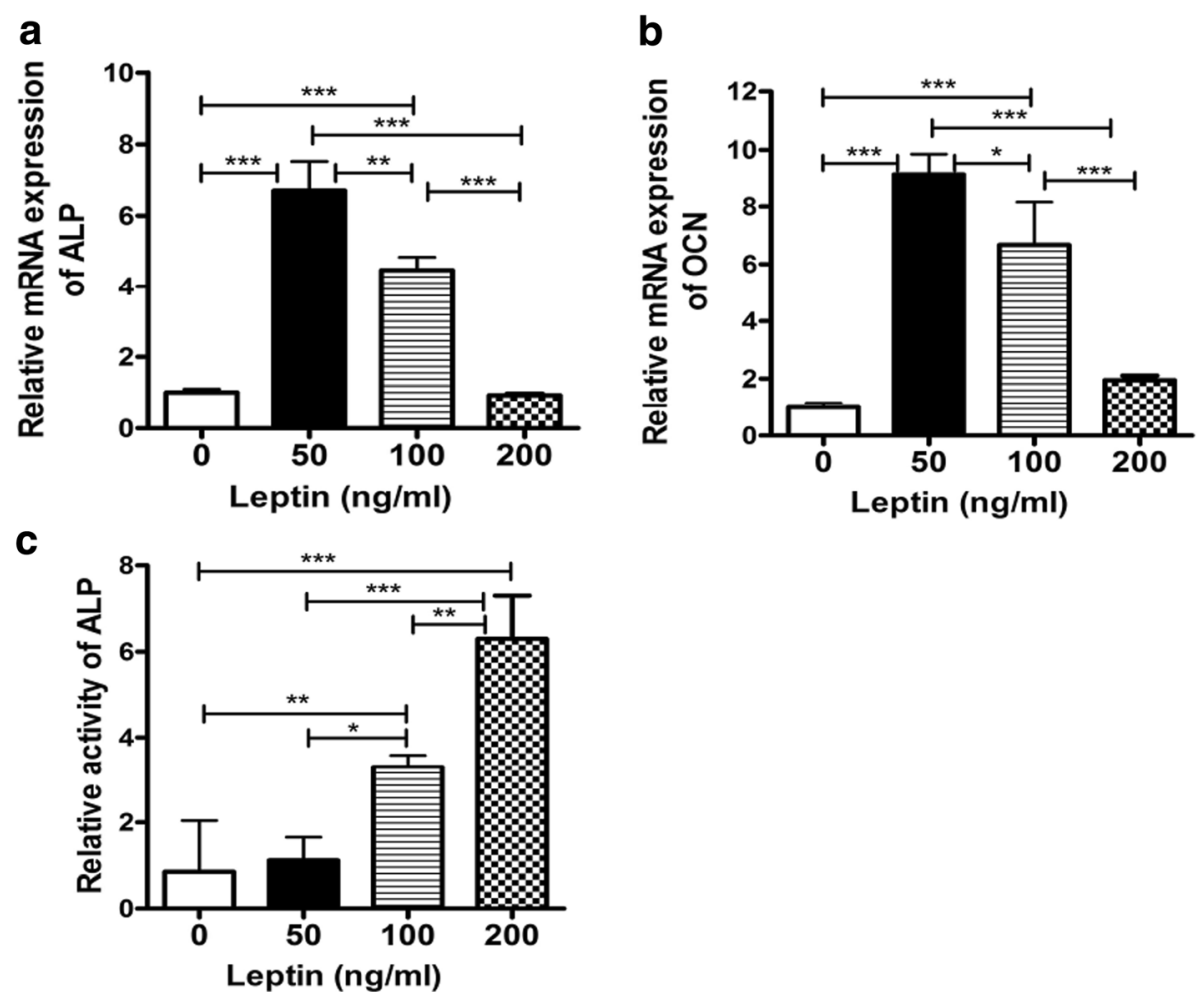

Fig. 3 Effects of leptin on osteocalcin and ALP mRNA expressions and activity in OPLL cells. a ALP mRNA expression. b OCN mRNA expression. c ALP activity measurement. ${ }^{*} p<0.05 ;{ }^{* *} p<0.001 ;{ }^{* * *} p<0.0001$ 

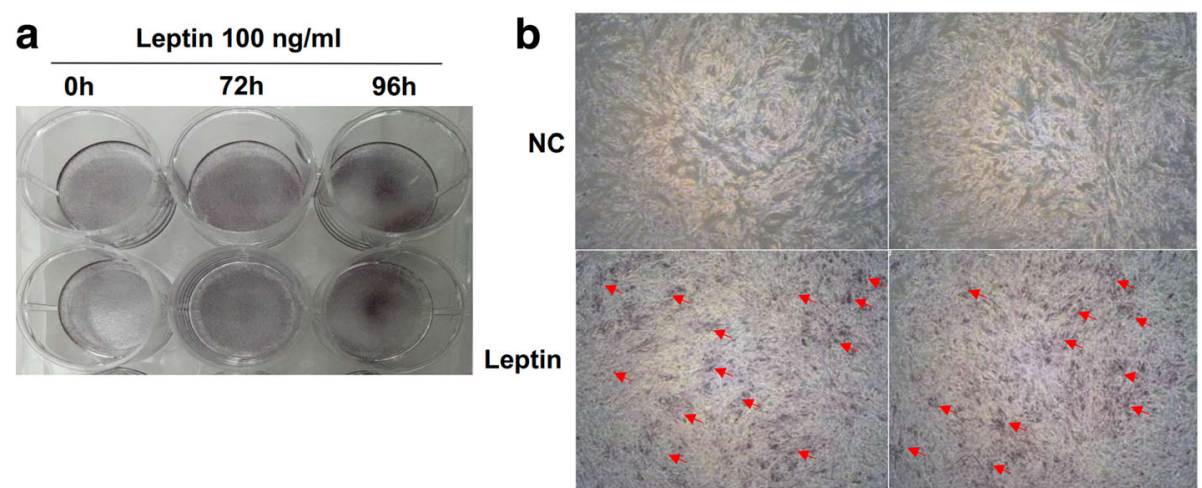

Fig. 4 Effects of leptin on the formation of mineralized nodules in OPLL cells. a Different time points of leptin stimulation. b Leptin (100 ng/ml) stimulated for $96 \mathrm{~h}$. Mineralized nodules are indicated by red arrows in the figure. NC, negative control

of the posterior longitudinal ligament. Obesity is considered to be the major risk factor of OPLL [5, 22]. Recent studies showed that hyperleptinemia, a common feature of obese people, was closely correlated with OPLL [18]. These studies suggest that leptin, an adipocyte-derived cytokine, plays a critical role in connecting at molecular levels the phenotypical manifestation of obesity and the pathological development of OPLL.

In this study, we firstly determined the association between serum leptin concentration and bone metabolic markers in patients with OPLL. Our results demonstrated that female subjects had significantly higher serum leptin concentration compared with male subjects, in both
OPLL and non-OPLL groups. Serum leptin/BMI ratio in the OPLL groups was higher than that in the non-OPLL groups $(p<0.05)$ in female subjects. However, there was no obvious difference in the male subjects. Further analysis indicated that the leptin/BMI ratio correlated negatively with the ALP concentrations in both OPLL male and female groups, whereas male groups showed a significant correlation $(r=-0.473, p<0.05)$. Nevertheless, there were only 11 subjects, and the individual difference was great, which resulted in no statistically significant difference. This result suggests that leptin can inhibit bone formation in vivo, which was in accordance with the report of Elefteriou et al. [23], which demonstrated in
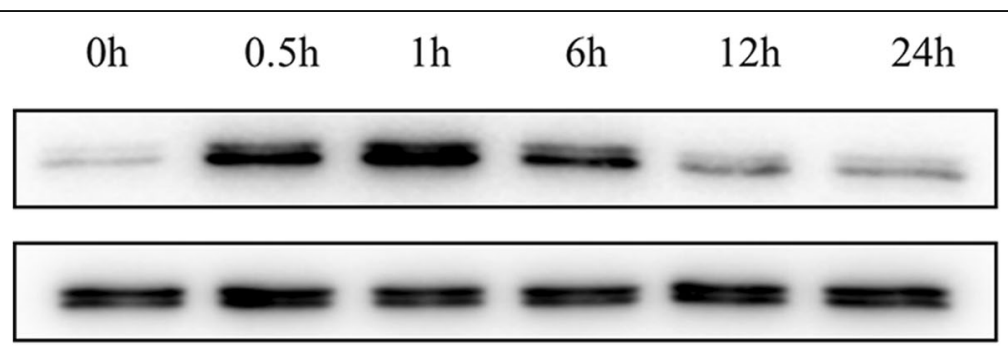

p-Erk1/2

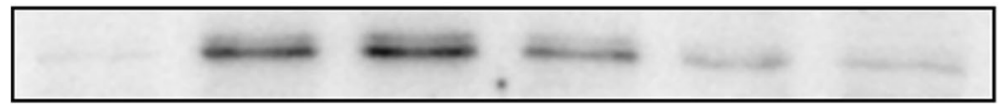

p-p38

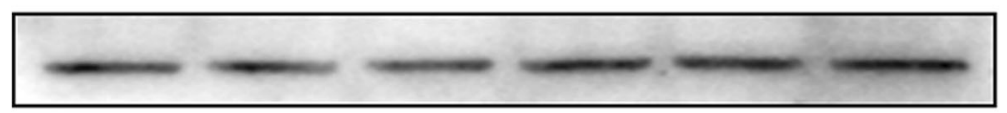

p38

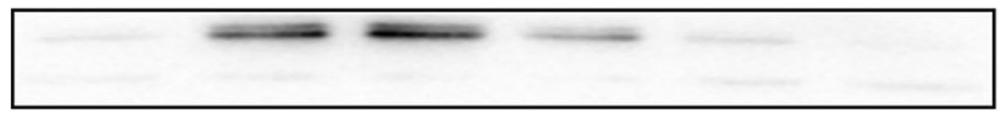

$\mathrm{p}-\mathrm{JNK}$

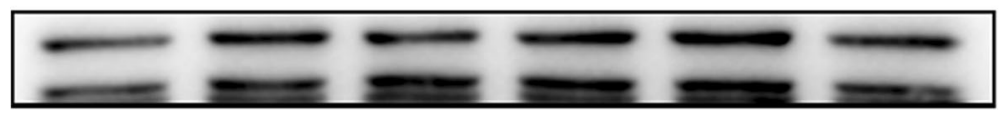

JNK

Fig. 5 Activation of ERK1/2, P38MAPK, and JNK signaling pathway in OPLL cells after $100 \mathrm{ng} / \mathrm{ml}$ leptin treatment 
animal experiments that leptin was a determinant of bone formation and leptin anti-osteogenic function was conserved in vertebrates. We also found that in the female group, the leptin/BMI ratio was weakly correlated positively with serum insulin levels in female OPLL, whereas the negative correlation was observed in male OPLL group, which was consistent with the previous studies [17, 24, 25].

To further validate the role of leptin in OPLL, we performed OPLL cell differentiation experiments in vitro. And the cell experiments were derived from multiple individuals. We found that leptin treatment can lead to a significant increase in mRNA expressions of ALP and OCN in OPLL cells; the effect was most significant at $50 \mathrm{ng} / \mathrm{ml}$ leptin concentration. ALP activity assay demonstrated that the activity of ALP was significantly elevated in response to leptin stimulation in a dose-dependent manner in OPLL cells. Furthermore, leptin can induce the cell matrix mineralization, nodules, and crystals in OPLL cells, whereas it had no appreciable effect on the proliferation of OPLL cells. Our findings prove that leptin plays an important role in osteogenic differentiation and mineralization of OPLL cells, which is consistent with the previous reports [26-28] that peripheral leptin was essential for normal bone resorption and enhancement of bone formation.

At the same time, in this study, we try to confirm the molecular mechanism involved in leptin-stimulated osteogenesis in OPLL cells. It is believed that leptin exerted its biological function through binding to its receptors, which in turn transduced the signal through the activation of specific pathways. Previous studies indicated that leptin can activate many signaling pathways involving the $\mathrm{JK} /$ signal transducer and activator of transcription (JAK/STAT), as well as PI3-K and MAPK, to regulate chondrocyte differentiation [29-33]. However, the involvement in leptin induction of osteogenic differentiation has not been studied. In our study, we found that leptin increased the expressions of ALP and $\mathrm{OCN}$ in a dose-dependent manner and the formation of mineralized nodule. At the same time, the phosphorylation of ERK1/2, JNK, and p38MAPK was activated by leptin. In summary, these results indicated that ERK1/2, JNK, and p38MAPK might be the signaling pathways mediating leptin-stimulated osteogenic differentiation in OPLL cells. This was helpful for the further studies on investigating the molecular mechanism underlying osteogenic commitment of OPLL cells.

The main limitation in this study was that the sample size was small, especially in the OPLL female group, which resulted in no statistically significant difference of the serum insulin concentrations between OPLL and non-OPLL females, as well as no significant correlations between leptin and both insulin and ALP. Nevertheless, even with the limitation of the sample size, in this study, our results were consistent with the results of preceding studies.

In conclusion, we found that leptin may negatively regulate bone formation in vivo, through a central hypothalamic relay, whereas positively promoted the osteogenic differentiation in vitro through the peripheral pathway as previous studies report [23, 28, 34]. Furthermore, activated ERK1/2, JNK, and p38MAPK signaling pathways might mediate leptin-stimulated osteogenic differentiation in OPLL cells. The results of our research may have significant enlightenment in understanding the mechanisms of spinal ligament growth. And further studies are needed to confirm our findings and to evaluate other possible mechanisms involved.

\section{Conclusions}

From this research, we found that serum leptin concentration was higher in female subjects compared with male subjects in both C-OPLL and non-OPLL groups. Serum leptin and ALP concentrations increased significantly in C-OPLL female compared to non-OPLL female. In both male and female with OPLL, the serum leptin concentration corrected for BMI correlated negatively with the ALP concentrations. In C-OPLL cells, leptin treatment led to a significant increase in mRNA expressions of ALP and OCN and the formation of mineralized nodule. The osteogenic effect of leptin in C-OPLL cells might be mediated via ERK1/2, p38 MAPK, and/or JNK signaling pathways.

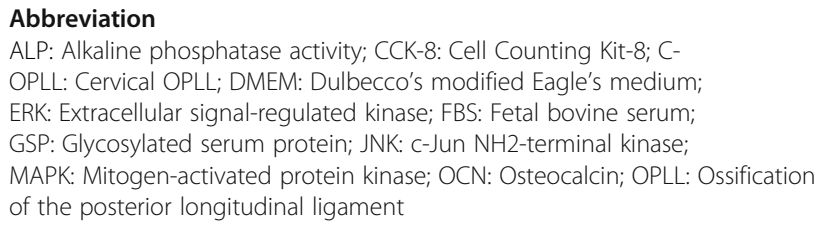

\section{Acknowledgements}

We acknowledge the assistance of Peking Union Medical College Central Laboratory with the technical guidance.

\section{Funding}

This study was supported by a grant from the National Natural Science Foundation of Youth in China (No. 81401758).

\section{Availability of data and materials}

The data of this study were real and were performed in SPSS (Version 19.0). The statistical results of the data are presented in the main paper. All of the data are available in contact with the correspondence author.

\section{Authors' contributions}

SLC and YR performed the experiments. JLZ and JHH analyzed and interpreted the data. BF, XSW, and YT devised the experiments and wrote the manuscript, with input from all co-authors. All authors read and approved the final manuscript. 


\section{Ethics approval and consent to participate}

Informed consent was obtained from all the individual participants included in the study. The study was conducted according to the Helsinki Declaration (Ethical Principles for Medical Research Involving Human Subjects) and was approved by the ethics committee of Peking Union Medical College Hospital.

\section{Consent for publication}

Not applicable.

\section{Competing interests}

The authors declare that they have no competing interests.

\section{Publisher's Note}

Springer Nature remains neutral with regard to jurisdictional claims in published maps and institutional affiliations.

Received: 28 February 2018 Accepted: 14 June 2018

Published online: 03 July 2018

\section{References}

1. Chen $Y$, Wang $X$, Yang $H$, et al. Upregulated expression of PERK in spinal ligament fibroblasts from the patients with ossification of the posterior longitudinal ligament. Eur Spine J. 2014;23:447-54.

2. Shi L, Cai G, Shi J, et al. Ossification of the posterior ligament is mediated by osterix via inhibition of the beta-catenin signaling pathway. Exp Cell Res. 2016;349:53-9.

3. Matsunaga S, Kukita M, Hayashi K, et al. Pathogenesis of myelopathy in patients with ossification of the posterior longitudinal ligament. J Neurosurg. 2002;96:168-72.

4. Kawaguchi Y, Nakano M, Yasuda T, et al. Serum biomarkers in patients with ossification of the posterior longitudinal ligament (OPLL): inflammation in OPLL. PLoS One. 2017;12:e0174881.

5. Nakajima M, Takahashi A, Tsuji T, et al. A genome-wide association study identifies susceptibility loci for ossification of the posterior longitudinal ligament of the spine. Nat Genet. 2014:46:1012-6.

6. Nakajima $\mathrm{M}$, Kou I, Ohashi $\mathrm{H}$, et al. Identification and functional characterization of RSPO2 as a susceptibility gene for ossification of the posterior longitudinal ligament of the spine. Am J Hum Genet. 2016;99:202-7.

7. Tanaka T, Ikari K, Furushima K, et al. Genomewide linkage and linkage disequilibrium analyses identify COL6A1, on chromosome 21 , as the locus for ossification of the posterior longitudinal ligament of the spine. Am J Hum Genet. 2003;73:812-22.

8. Tsuyama N. Ossification of the posterior longitudinal ligament of the spine Clin Orthop Relat Res. 1984;(184):71-84.

9. Jiang $\mathrm{H}$, Chen $\mathrm{Y}$, Chen $\mathrm{G}$, et al. Leptin accelerates the pathogenesis of heterotopic ossification in rat tendon tissues via MTORC1 signaling. J Cell Physiol. 2018;233(2):1017-28.

10. Philbrick KA, Wong CP, Branscum AJ, et al. Leptin stimulates bone formation in ob/ob mice at doses having minimal impact on energy metabolism. J Endocrinol. 2017;232:461-74.

11. Fan $D$, Chen $Z$, Chen $Y$, et al. Mechanistic roles of leptin in osteogenic stimulation in thoracic ligament flavum cells. J Biol Chem. 2007;282:29958-66.

12. Zheng B, Jiang J, Luo K, et al. Increased osteogenesis in osteoporotic bone marrow stromal cells by overexpression of leptin. Cell Tissue Res. 2015:361:845-56

13. Lamghari M, Tavares $L$, Camboa N, et al. Leptin effect on RANKL and OPG expression in MC3T3-E1 osteoblasts. J Cell Biochem. 2006;98:1123-9.

14. Motyl KJ, Rosen CJ. Understanding leptin-dependent regulation of skeletal homeostasis. Biochimie. 2012;94:2089-96.

15. Steppan CM, Crawford DT, Chidsey-Frink KL, et al. Leptin is a potent stimulator of bone growth in ob/ob mice. Regul Pept. 2000;92:73-8.

16. Ducy P, Amling M, Takeda S, et al. Leptin inhibits bone formation through a hypothalamic relay: a central control of bone mass. Cell. 2000;100:197-207.

17. Ikeda Y, Nakajima A, Aiba A, et al. Association between serum leptin and bone metabolic markers, and the development of heterotopic ossification of the spinal ligament in female patients with ossification of the posterior longitudinal ligament. Eur Spine J. 2011;20:1450-8.
18. Shirakura $Y$, Sugiyama $T$, Tanaka $H$, et al. Hyperleptinemia in female patients with ossification of spinal ligaments. Biochem Biophys Res Commun. 2000;267:752-5.

19. Scotece M, Mobasheri A. Leptin in osteoarthritis: focus on articular cartilage and chondrocytes. Life Sci. 2015;140:75-8.

20. Upadhyay J, Farr OM, Mantzoros CS. The role of leptin in regulating bone metabolism. Metabolism. 2015;64:105-13.

21. Vuolteenaho K, Koskinen A, Moilanen E. Leptin - a link between obesity and osteoarthritis. Applications for prevention and treatment. Basic Clin Pharmacol Toxicol. 2014;114:103-8.

22. Shingyouchi Y, Nagahama A, Niida M. Ligamentous ossification of the cervical spine in the late middle-aged Japanese men. Its relation to body mass index and glucose metabolism. Spine. 1996;21:2474-8.

23. Elefteriou F, Takeda S, Ebihara K, et al. Serum leptin level is a regulator of bone mass. Proc Natl Acad Sci U S A. 2004:101:3258-63.

24. Akune T, Ogata N, Seichi A, et al. Insulin secretory response is positively associated with the extent of ossification of the posterior longitudinal ligament of the spine. J Bone Joint Surg. 2001;83a:1537-44.

25. Dagogo-Jack S, Fanelli C, Paramore D, et al. Plasma leptin and insulin relationships in obese and nonobese humans. Diabetes. 1996;45:695-8.

26. Cornish J, Callon K, Bava U, et al. Leptin directly regulates bone cell function in vitro and reduces bone fragility in vivo. J Endocrinol. 2002:175:405-15.

27. Zheng B, Jiang J, Chen Y, et al. Leptin overexpression in bone marrow stromal cells promotes periodontal regeneration in a rat model of osteoporosis. J Periodontol. 2017;88:808-18.

28. Turner RT, Kalra SP, Wong CP, et al. Peripheral leptin regulates bone formation. J Bone Miner Res Off J Am Soc Bone Miner Res. 2013;28:22-34.

29. Ben-Eliezer M, Phillip M, Gat-Yablonski G. Leptin regulates chondrogenic differentiation in ATDC5 cell-line through JAK/STAT and MAPK pathways. Endocrine. 2007;32:235-44

30. Nepal M, Li L, Cho HK, et al. Kaempferol induces chondrogenesis in ATDC5 cells through activation of ERK/BMP-2 signaling pathway. Food Chem Toxicol. 2013;62:238-45.

31. Oh HK, Choi YS, Yang YI, et al. Leptin receptor is induced in endometriosis and leptin stimulates the growth of endometriotic epithelial cells through the JAK2/STAT3 and ERK pathways. Mol Hum Reprod. 2013;19:160-8.

32. Ohba S, Lanigan TM, Roessler BJ. Leptin receptor JAK2/STAT3 signaling modulates expression of Frizzled receptors in articular chondrocytes. Osteoarthr Cartil. 2010:18:1620-9.

33. Otero M, Lago R, Gómez R, et al. Phosphatidylinositol 3-kinase, MEK-1 and p38 mediate leptin/interferon-gamma synergistic NOS type II induction in chondrocytes. Life Sci. 2007;81:1452-60.

34. Chen XX, Yang T. Roles of leptin in bone metabolism and bone diseases. J Bone Miner Metab. 2015:33:474-85.

\section{Ready to submit your research? Choose BMC and benefit from:}

- fast, convenient online submission

- thorough peer review by experienced researchers in your field

- rapid publication on acceptance

- support for research data, including large and complex data types

- gold Open Access which fosters wider collaboration and increased citations

- maximum visibility for your research: over $100 \mathrm{M}$ website views per year

At BMC, research is always in progress.

Learn more biomedcentral.com/submissions 